\title{
Immersive Ars Memoria: Evaluating the Usefulness of a Virtual Memory Palace
}

\author{
Jan-Paul Huttner \\ Technische Universität \\ Braunschweig \\ i-p.huttner@tu-bs.de
}

\author{
Kathrin Robbert \\ Technische Universität \\ Braunschweig \\ k.robbert@tu-bs.de
}

\author{
Susanne Robra-Bissantz \\ Technische Universität \\ Braunschweig \\ $\underline{\text { s.robra-bissantz@tu-bs.de }}$
}

\begin{abstract}
The Method of Loci (also memory palace) is the most powerful mnemonic strategy and was widely analyzed over the last twenty years. Especially, the approach to combine this ancient learning method with modern technology got more and more into the focus of an interdisciplinary research community. Researchers presented their students virtual environments via computer screen or head-mounted displays and instructed them to use these virtual worlds as a template for a memory palace. However, most studies did not investigate the users' attitude to actually use such a tool in everyday situations. This study addresses this research gap by an experiment and a correlation and regression analysis. Results show significant correlations between the learning success and important factors of the users intention to use a virtual memory palace.
\end{abstract}

\section{Introduction}

This study aims to address researchers and practitioners in the domain of learning and teaching technologies.

The ancient mnemonic called Method of Loci (MOL, also memory palace) describes a learning a strategy that is based on the principle of mentally associating learning content with spatial cues. Yates (1966) emphasized that this way of associating information facilitates the process of memorization and recall [51]. Hence, according to Krathwohl's revised taxonomy of learning (originally introduced by Bloom, 1956 [5]), the first level of learning, "remembering" [30], can be facilitated using mnemonic strategies like the MOL.

The idea to integrate mnemonics in the students' curriculum was brought up by several researchers. For instance, Hartwig, Dunlosky and McCabe described the potential lying in these methods and how these would foster the students' chance to succeed in college [19, 40]. Additionally, in 2015 Putnam outlined the positive correlation between the use of mnemonics and the students' motivation to learn. He explained that the time which is saved by learning the basic principles using mnemonics can be used to focus on higher order learning.

Still, mnemonic strategies are not fully integrated in the educational system or in the students curriculum [43].

\subsection{Method of Loci}

As already mentioned, the MOL is the underlying principle of a memory palace. The idea is to mentally associate declarative information with spatial cues. So, if a learner wants to apply the MOL or build a memory palace, $\mathrm{s} /$ he has to place the learning content in different and well-known places (place = lat. locus, pl. loci). These loci then serve as navigation points when traversing the memory palace. For instance, supposed a student wants to memorize a list of important hardware components of a computer. Then s/he mentally walks through her/his apartment or house and puts the CPU into the sink, the motherboard in the oven, the keyboard on the kitchen table and so on. Later, if the student wants to recall these hardware items, s/he mentally traverses her/his home again and collects the items one after another.

This simple principle of connecting information to locations results in remarkably better retention performance that rote rehearsal. Nevertheless, to successfully apply the MOL or build a memory palace, a certain time of training is necessary. Especially, if amount of learning content grows or becomes more complex. Authors reported different training phases ranging between a few hours several days [7, 47].

Memory palaces and the MOL are investigated from an interdisciplinary research community ranging from the educational perspectives over computer scientific approaches up to neuroscientific studies $[13,36]$. 


\subsection{Virtual Memory Palaces}

At the end of the $90 \mathrm{~s}$, researchers in the computer science and psychology domain began to combine modern technology with the ancient principles of mnemonic strategies. In this research stream, the traditional MOL (respectively memory palace) was enhanced with the idea of using a virtually presented environment as a template for the mental representation of one's memory palace. In the following, this combination of virtual environment and memory palace will be referred to as a virtual memory palace (VMP).

As described in the next section, the concept of a VMP implicates an interesting potential for educational purposes, especially regarding the rising trend of virtual reality.

\section{Related Work}

Over the last two decades various studies investigated a variety of research questions regarding VMPs. For instance, does a VMP outperform the traditional MOL or can a VMP increase the long term memory. In the following, a brief description of the relevant studies (section two) and the derived research motivation for this study will be given (section three).

Storkerson and Wong (1997) were the first authors to introduce the underlying principle of a VMP. They described their approach as enhancing mnemonic strategies with the help of hypermedia. Authors argued that an increased level of intelligibility of communications should improve the memorization process with spatial cues [50].

Three years later, Hedman and Bäckström built a rudimental VMP to support their students in a course of philosophy [20]. The VMPs architecture was quite similar to a traditional museum and the loci were designed as white canvases with philosophy related learner's text on it. Interestingly, the VMP was already designed for a real-life educational purpose. Nevertheless, an experiment with only a few students did not show any superior learning success compared to conventional methods. Moreover, the question of whether the students actually appreciate such tool was not further analyzed.

In 2006, a study of Fassbender and Heiden implemented a VMP which was inspired by medieval castles. They also conducted a study to evaluate the long term memory and reported a positive feedback from the students. However, again a deeper investigation of the users' intention to use a VMP in everyday situations was not carried out [15].

Six years later, Legge et al. (2012) conducted a wide experiment involving three groups of students $(\mathrm{N}=142)$ to show whether the traditional MOL outperforms a VMP or vice versa. So two groups were told to either use the traditional MOL or were given a VMP to apply the MOL. The third one was a control group (without instructions to use a specific learning strategy). This control group was clearly outperformed by the other two. However, there was no significant difference of the recall performance between the two experimental groups. An analysis of the participants' attitude towards using a VMP was not part of the study [32].

In 2016, Jund et al. analyzed the design of a VMP regarding two different frames of reference. Therefore, they compared two groups of participants and their recall performance depending on the frame of reference. As a result, they stated that an egocentric frame is better suited for the design of a VMP than an allocentric one. However, the participants' opinion of the concept was not investigated. Nevertheless, authors emphasized that the level of immersion is a crucial factor for the concept of a VMP. Immersion describes the perception of being in a certain place although one is physically in another [49].

In the same year Huttner et al. (2016) proposed and underlined the factor of immersion as crucial for a VMP, which was followed by an experiment in 2017 [24, 25]. Results indicated a superiority of high immersive VMP concepts. A similar approach was followed and confirmed by Krokos et al. (2018) [31].

Further studies were conducted in the years 2017 and 2018 but none of them addressed the users' perceived usefulness or similar factors to predict the actual intention to use such a system $[17,38,46]$.

\section{Theory \& Research Approach}

This study is thought to overall contribute to the research domain of VMPs and to outline the potential for practical solutions which lies in this concept. The design science research methodology (DSRM) is a fitting framework to address the aim of practical IS solutions. That is why this study shall be assigned to the DSRM process as introduced by Hevner et al. (2004) [22], more precisely the refinement of Peffers et al. (2007) [42]. Their description of the DSRM includes six consecutive phases, starting from the definition of a problem, followed by the theoretical base for a better solution, a verifiable artefact and its demonstration plus evaluation and finally the communication of the findings. Striving for a practical concept of a VMP, this study aims to support the second step in the DSRM. So, the results of this experiment should expand the theoretical base and encourage further approaches towards VMPs in real-life educational contexts. 
As seen in section two, prior research already investigated many crucial aspects for the concept of a VMP. Nevertheless, the user's opinion towards the virtual MOL was not part of the studies yet. Especially if a research stream focuses on practical solutions (e.g. by the DSRM), the users' perceived usefulness (PU) of the artefact is a central component [42][28][4]. Since the main purpose of a VMP is to improve the users' recall performance, the hypothesized effect is a positive influence of the recall performance on the users' PU. In this study, the PU is measured using the well-established latent variable PU of Davis' Technology Acceptance Model (TAM) from 1989. He described PU as "the degree to which a person believes that using a particular system would enhance his or her job performance" [11]. Hence, the original questionnaire items aim to evaluate the technology acceptance of a an information system in a work context. Therefore, in this experiment the items of the constructs were changed to the context of the VMP and the educational setting.

The recall performance is measured using the scoring system introduced by Legge et al. in 2012 [32]. Their rating of the recall performance consisted of two different scores, the strict and the lenient score. The strict score reflects how many terms a participant was able to recall in the correct order. The lenient score simply calculates as the percentage of correct recalled terms, ignoring the order. For instance, the participant is presented a list consisting of the five the fork, table, apple, spoon and smartphone. Then, if the participants' recalled list would be fork, table, spoon, apple and tablet, the lenient score would be 0.8 since only smartphone was missing. A more detailed description of how the strict score was calculated is given in section five due to the more complex calculation and the analysis related importance.

However, the first two hypotheses are derived as follows:

H1: The users' achieved lenient score (short term) significantly predicts a positively correlated Perceived Usefulness

H2: The users' achieved strict score (short term) significantly predicts a positively correlated Perceived Usefulness

Another aspect that was already investigated to some degree is the factor immersion, respectively its influence on the recall performance in a VMP. Referred to the theory, this effect makes sense since a higher level of immersion has several beneficial effects on crucial elements of learning. Authors mentioned positive correlations between the level of immersion and a decreased cognitive burden, an increased enjoyment or engagement and better memorization $[1,6,12,34,35$, $37,44,45,49]$.

As described in section two, two studies investigated the recall performance and the level of immersion. The experiments included two groups that were given different displays for the use of the VMP. Results indicated a superiority of more immersive displays like a HMD $[25,31]$. However, both studies did not actually measure the level of immersion but rather compared two different types of displays like a desktop screen and a HMD. Therefore, this study involves a questionnaire to assess the participants' level of immersion. Agarwal et al. (2000) suggested a five-item construct called Focused Immersion (FI) which was originally built for the analysis of immersive web applications [1]. Again, the items were slightly rewritten to fit the context of the VMP. Hence, the last two hypotheses are the following:

H3: The users' level of immersion significantly predicts a positively correlated strict score

H4: The users' level of immersion significantly predicts a positively correlated lenient score

Summarized, this study focuses on the participants ability to recall information and the possibly correlated perceived usefulness as a crucial factor for practical VMP solutions in future research. Also the level of immersion shall be analyzed as a driving factor for the recall performance. That is why the other TAM constructs are not analyzed in detail.

As already mentioned, the hypotheses were evaluated by an experiment with a paired sample. A more detailed description is given in section four.

\section{Experimental Design}

This section gives a brief description of the experimental context including the participants, the VMP prototype and technology as well as the procedure. As described above, the recall accuracy was operationalized as the strict and lenient scores. Therefore, a list of words served as the to-beremembered items. This list was not composed randomly but consisted of 40 terms. The amount of 40 was suggested by Ross and Lawrence (1968)[48], especially for the evaluation of the MOL. In addition to that, all of the terms were highly concrete. This design aspect was chosen in order to lower the participants (mostly beginner level) effort to visualize the to-beremembered items. As explained earlier, the successful application of the MOL heavily depends on the ability to create mental images in one's mind. This aspect was also described by Legge et al. (2012)[32], they 
mentioned that terms of a high concreteness are overall easier to remember than abstract (low concreteness) words. For instance, a term that has a high concreteness would be table, which is easier to visualize than a term like wisdom. Therefore, the list of terms was taken from a study performed by Kanske and Kotz in 2010. They used a survey to evaluate approx. 1000 words and their corresponding norms, e.g. the level of concreteness [27].

Howsoever, participants were told to apply the vMOL by the help of the VMP prototype. So, the subjects had to traverse the VMP in a predefined path (due to the static position of the loci) and memorize the loci. A more detailed description of the technology, the prototype, the participants and the procedure will be given in the following sections.

\subsection{Technology}

In section three, the important role of an immersive display for the application of a VMP was already described. In order to offer the users an immersive experience, at least more immersive than a common computer screen [45], the VMP was built for a headmounted display (HMD). More precisely, it was implemented as a virtual reality (VR) environment. This design decision is also encouraged by the potential lying in the VR technology for educational purposes, especially at a time in which the necessary hardware becomes more and more affordable for the majority of the people [39].

In detail, the VMP environment was generated as a smartphone application (developed with Unity 3D). The smartphone was then put into a goggle that integrates the phone as a stereoscopic display. Two lenses in the goggle project the two separated images into the user's eyes (see figure 1). Based on this mechanism, the user perceives the environment in three dimensions. So, every participant was given such a HMD plus a wired gaming controller to navigate through the virtual world. In addition to that, every subject was put on a swivel chair to easily look around in the VR (the head movement was tracked and translated by the application). Also, this should avoid possible problems with the subjects' sense of balance while traversing the VMP.

\subsection{Prototype}

The prototype did not only consist of the VMP itself, but also offered each participant a mandatory training level. In this manner, the procedure ensured that the users understood how to walk around and how to interact with the loci. After passing the training level, the user was spawned into the VMP and the memorization task began. As shown in Figure 1, each locus consists of a combination of text (in this case "Zeitung", engl. newspaper) and a corresponding sketchy image.

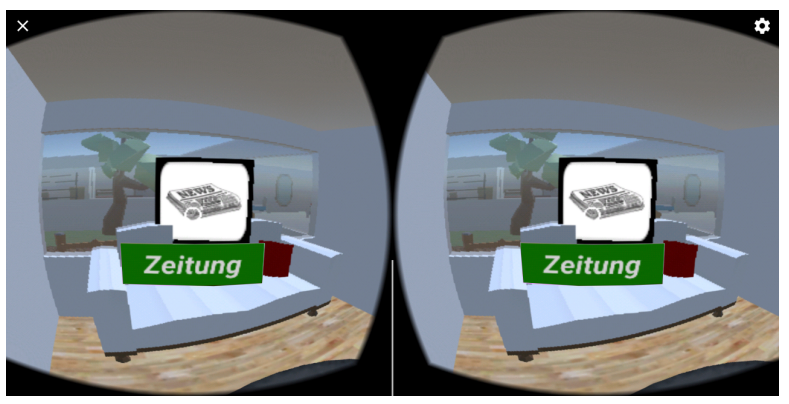

Figure 1. Stereoscopic screenshot of a locus

The VMP was designed as an apartment (similar to Legge et al. 2012 [32]). The loci were implemented at fixed positions, so the order of the to-be-remembered terms did not vary. The user started the memorization task at the entrance of the apartment. The first locus was placed at the spawn position. However, the loci were not visible all the time in order to reduce a bias caused by the time a participant chose to actually look at a specific locus. Therefore, each locus was initially hidden in a floating square with a question mark on it. A fixed dot in the center of the field of view served as a selection cursor. So, the user had to focus the dot on the square and press a controller button to reveal the locus (e.g. term and image). After that, the locus was uncovered for five seconds and then disappeared, so participants only had a limited timespan (adopted from Legge et al. (2012)[32]) to memorize the term. Furthermore, every following locus (square with question mark) appeared right after the antecedent one disappeared. That way, the order in which the terms were presented to each participant was always the same.

\subsection{Participants}

Overall, 47 undergraduate students took part in the experiment. Most of them major in technically fields of study. Note that the students were not incentivized in any manner to participate in the study. German was required to be the participants' mother tongue since the list of terms were also in German. Hence, a bias due to misunderstandings was avoided.

Another possible biasing factor was the problem of motion sickness (MS). Participants partly suffered from MS due the VR experience. It is an effect that might occur if the user perceives a discrepancy between the visual stimulus and her/his actual head movement [21]. As a result, the subjects' level of immersion drops and they cannot longer focus on the task [49]. Four of the students had to quit the memorization task due to MS. 
Hence, these four were removed from the dataset leaving a sample of 43 participants (female $=17$, male $=26$, aged between 18 and 29 , mean $=24,00)$. Later in the long term recall phase, 30 of them took part. All of the participants had only little to none prior experience in the application of the MOL.

\subsection{Procedure}

The experiment was conducted over a timespan of roughly six weeks. Each participant performed under the same conditions. Figure 2 shows the six phases each student had to master. In phase one, each subject was instructed on how the MOL works and how to apply it. Then, participants were handed the HMD and the gaming controller. The training level started and the subjects had to walk around and activate an example loci to understand and become confident with the handling. After fulfilling this task, they were spawned into the VMP and the memorization phase started. This phase did not have a time limit but on average, participants spend 628,526 seconds in the VMP (std. dev. = 192,177 seconds). After the students finished the memorization task, they were given a website to enter the 40 terms. The design of the website was closely aligned to the one described by Legge et al. (2012)[32]. First, a brief description was given on how to enter the terms. Participants were asked to enter one term after another. The page consisted of a white background with only a single input field in the center of the display and a submit button.

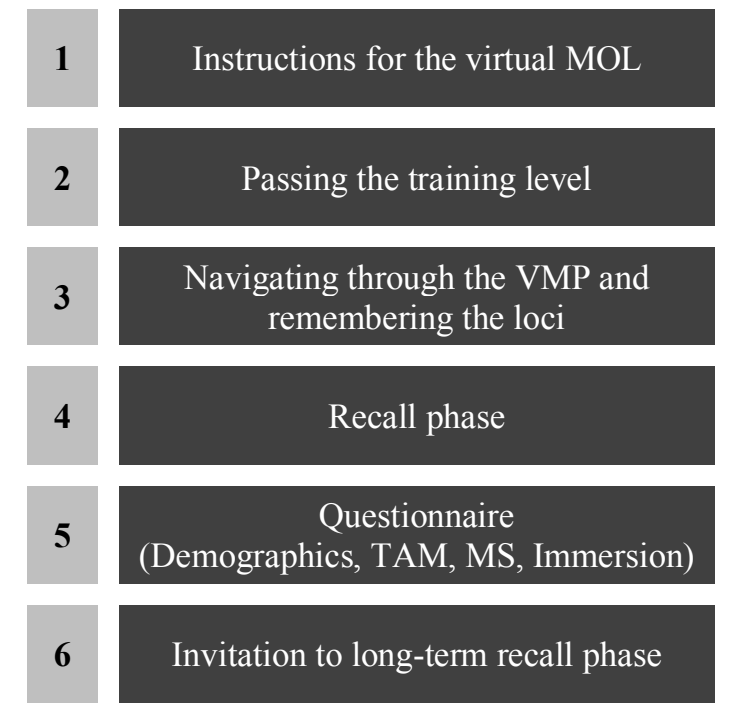

Figure 2. Experimental Procedure

In the fifth phase, the students received a questionnaire to collect their demographic information plus the Likert-scaled items of the TAM, FI and motion sickness. The last phase intended to test the subjects' long term memory. So, after one week they were asked via e-mail to repeat the recall phase. By following a hyperlink they were referred to the exact same interface of phase four. Overall 30 students completed this long term recall phase. Note that the students were not informed about the long-term recall task in advance.

\section{Analysis \& Results}

Before the data was analyzed, the following revision steps were carried out. First, the subjects' input was revised. As explained in section three, the learning success was operationalized as the strict and lenient scores. Hence, these scores represent two different approaches of calculating the amount of words each participant was able to remember. One respected the right order (strict score) the other one did not (lenient score). While reviewing the input in the database, in some cases spelling mistakes were found or participants chose a wrong pluralization. These kind of mistakes were not considered as representative factors for the participants memorization accuracy. Therefore, these terms were corrected (e.g. foork or forks were afterwards changed to fork, but only if it did not change the original meaning of the term). The lenient score was simply calculated as the percentage of the correct terms that occurred in the participants input. The strict score was calculated using the levenshtein distance (also edit distance). This algorithm is used to calculate the minimum costs of transforming one sequence (e.g. a string or an array of terms) into an original one [33]. The algorithm includes three basic operations: replace, delete and insert. Every time the algorithm has to use one of them, a counter increments the costs of transformation by one. In the end, the minimum costs are returned. For instance, the original sequence is table, spoon, fork, apple, banana while the user's input was spoon, fork, apple, banana, table. In this case, the order is almost perfect except for the term table. The levenshtein distance then deletes table and adds it at the beginning of the sequence. Hence, two operations were performed (deletion and insertion) and the cost of transforming the sequence is two. The strict score was then computed using the following formula:

$$
\text { strict score }=1-\operatorname{lev}(u, 0) / \max
$$

The function $\operatorname{lev}(\mathbf{u}, \mathbf{0})$ returns the levenshtein costs of the user input sequence $\mathbf{u}$ and the original sequence $\mathbf{o}$. The value max represents the maximum amount of operations that might be necessary to transform any given sequence of terms (worst case scenario, in this setting it is the maximum length of the original sequence) into the original one. Hence, regarding the 
example the strict score would be $\mathbf{1}-\mathbf{2} / \mathbf{5}=\mathbf{0 . 6}$. This way of computing the strict score ensures an objective measure of the subjects ability to recall the terms in order. Furthermore, an increasing recall performance results in an increasing strict score that ranges between 0 and 1 . Table 1 gives an overview to the descriptive statistics of the variables (with $\mathrm{N}=43$, as mentioned in section 4.3).

\section{Table 1. Descriptive Data}

\begin{tabular}{l|rrr} 
Variable & Mean & Median & Std.Dev. \\
\hline $\begin{array}{l}\text { Strict score } \\
\text { (short term) }\end{array}$ & 0,404 & 0,375 & 0,267 \\
\hline $\begin{array}{l}\text { Strict score } \\
\text { (long term*) }\end{array}$ & 0,298 & 0,225 & 0,283 \\
\hline $\begin{array}{l}\text { Lenient score } \\
(\text { short term) }\end{array}$ & 0,707 & 0,725 & 0,186 \\
\hline $\begin{array}{l}\text { Lenient score } \\
\text { (long term*) }\end{array}$ & 0,606 & 0,625 & 0,256 \\
\hline $\begin{array}{l}\text { Focused } \\
\text { Immersion }\end{array}$ & 5,502 & 6,000 & 1,118 \\
\hline $\begin{array}{l}\text { Perceived } \\
\text { Usefulness }\end{array}$ & 4,810 & 5,000 & 1,395 \\
\hline$* \mathrm{~N}=30$ & & &
\end{tabular}

As seen in the data, the participants' average recall performance dropped within one week by $26 \%$ regarding the strict score and $14 \%$ regarding the lenient score. So, the ability to recall the terms in order, decreased relatively further than the general recall performance. The mean and median of the variables Focused Immersion and Perceived Usefulness lie above the average of 4 and therefore indicate a positive tendency.

\subsection{Model Fit and Internal Validity}

In order to determine the correctness of the measures, a confirmatory factor analysis (CFA) was performed on the latent variables (TAM and Focused Immersion)(see table 2).

Table 1. Model Fit Indices

\begin{tabular}{l|rr} 
Model Fit Index & FI & TAM \\
\hline Model Fit Test Statistic & 16,202 & 122,801 \\
\hline Degrees of Freedom & 5 & 74 \\
\hline Chi-Square (p-value) & 0,006 & 0,000 \\
\hline Comparative-Fit-Index (CFI) & 0,913 & 0,940 \\
\hline Tucker-Lewis-Index (TLI) & 0,826 & 0,926 \\
\hline
\end{tabular}

\begin{tabular}{l|cc}
\hline $\begin{array}{l}\text { Root Mean Square Error } \\
\text { of Approximation (RMSEA) }\end{array}$ & 0,012 & 0,004 \\
\hline $\begin{array}{l}\text { Standardized Root Mean Square } \\
\text { Residual (SRMR) }\end{array}$ & 0,069 & 0,064 \\
\hline
\end{tabular}

The data analysis was conducted using SPSS (version 25). The RMSEA $(<0.05)$, the SRMS $(<0.08)$, the CFI $(>0.9)$ and the TAM related TLI $(>0.9)$ are at least satisfactory $[2,16,18,23,29]$. The TLI of Immersion is below the recommended threshold. Although not perfect, the resulting model fit indices indicate a sufficient reliable data set for this purpose. A slightly better model fit would certainly refine the results in future experiments. Cronbach's alpha indicates very good results for the internal validity that are above 0.8 and 0.9 (see table 3)[10]. Note that none of the respecting variable items had to be dropped in order to increase the internal validity.

\section{Table 3. Internal Validity}

\begin{tabular}{l|r} 
Variable & Cronbach's Alpha \\
\hline Immersion & 0,831 \\
\hline PEOU & 0,932 \\
\hline PU & 0,943 \\
\hline BIU & 0,984 \\
\hline TAM & 0,928
\end{tabular}

In the following, the assumed relations between the recall performance and the user's perceived usefulness, as well as the immersion and the recall performance was investigated by performing a correlation analysis.

\subsection{Regressions}

In order to check and model the hypotheses, corresponding linear regressions were calculated if a correlation was found on a significant level $(p<.05)$ or at least a trend effect of $p<0.1$. Note that due to a lack of normally distributed data and the ordinal scaled TAM items, correlations were calculated using Spearman's Rho [3]:

Table 4. Regression Models

$\begin{array}{llll}\text { H1: Strict_st (independent), PU (dependent) } & \\ \text { Std. error } & \text { Beta }^{1} & \text { F-Stat. } & \text { Adj. R2 } \\ 0,740 & 0,420 & 8,797 & 0,157^{* *} \\ \text { Cohen's D } & \text { Corr. } & \text { N } & \\ 0,4315 & 0,420^{* *}(\mathrm{~S}) & 43 & \end{array}$


H2: Lenient st (independent), PU (dependent)

\begin{tabular}{llll} 
Std. error & Beta $^{1}$ & F-Stat. & Adj. R2 \\
1,057 & 0,426 & 9,064 & $0,161^{* *}$ \\
\hline Cohen's D & Corr. & N & \\
0,4380 & $0,392 * *(S)$ & 43 &
\end{tabular}

\begin{tabular}{llll}
\hline H3: FI (independenz), Strict_st (dependent) & \\
\hline Std. error & Beta $^{1}$ & F-Stat. & Adj. R2 \\
0,041 & 0,271 & 3,181 & $0,051^{\circ}$ \\
\hline Cohen's D & Corr. $^{\circ}$ & N & \\
0,2318 & $0,302^{\circ}(\mathrm{S})$ & 43 &
\end{tabular}

\begin{tabular}{|c|c|c|c|}
\hline $\begin{array}{l}\text { Std. error } \\
0,028\end{array}$ & $\begin{array}{l}\text { Beta }^{1} \\
0,310\end{array}$ & $\begin{array}{l}\text { F-Stat. } \\
4,260\end{array}$ & $\begin{array}{l}\text { Adj. R2 } \\
0,074^{*}\end{array}$ \\
\hline Cohen's D & Corr. & $\mathbf{N}$ & \\
\hline 0,2827 & $0,307 *(\mathrm{~S})$ & 43 & \\
\hline \multicolumn{4}{|c|}{$\begin{array}{l}\text { Significance: }{ }^{\circ} \mathrm{p}<0,1 \text { (trend effect); }{ }^{*} \mathrm{p}<0,05 ; * * \mathrm{p}<0,01 \\
(\mathrm{~S})=\text { Spearman's Rho; }{ }^{1}=\text { Standardized; } \\
\text { Strict_st }=\text { Strict score (short term); Lenient_st }=\text { Lenient } \\
\text { score } \mathbf{( s h o r t ~ t e r m ) ; ~ P U ~ = ~ P e r c e i v e d ~ u s e f u l n e s s ; ~ F I . ~ = ~ F o c u s e d ~} \\
\text { Immersion }\end{array}$} \\
\hline
\end{tabular}

Except for the influence from the factor immersion on the strict score, every other assumed model is significant on a level below .05 and shows at least an approx. average effect size (Cohen's D: average $>.25$, strong $>$.40)[9]. The corresponding coefficients of determination (r-squared) show a moderate (H1 \& H2) and a weak (H3 \& H4), but yet notable proximity of the data to the model (substantial: $<.26$, moderate: $<.13$, weak < .02)[8]. The recall performance moderately explains the users' perceived usefulness while the level of immersion slightly predicts the recall performance. Hence, the assumed effects are not really strong, but still, they exist and support the described theory. Furthermore, the data analysis revealed a positive correlation between immersion and $P U$ (Spearman's Rho: $0.505, \mathrm{p}<.01)$ as well as immersion and $B I U$ (Spearman's Rho: 0.483, p < 0.01). Therefore, in the context of a VMP, the level of immersion might play an important role for the technology acceptance and certainly is an interesting issue for further studies in this domain.

\subsection{Limitations}

Since this study involved a laboratory experiment, some limitations need to be mentioned. The participants were exclusively and technically oriented undergraduates in their mid-twenties. In order to improve the representativity, future studies should try to find more diverse participants. Furthermore, the used instrument to measure the level of immersion (focused immersion [1]) had the lowest internal validity compared to the TAM variables. Maybe another, more extensive questionnaire could improve the measurement (e.g. Witmer and Singer (1998)[49]). Another limitation needs to be outlined regarding the last phase of the experiment. Since the invitation to the long term recall task was sent via e-mail, one week later, we could hardly ensure that participants took part immediately. Although we did not inform the students about the longterm recall task, it is also possible, that some of them anticipated this phase and wrote down the terms right after the initial experiment. Furthermore, in order to evaluate the long term recall performance more elaborately, a control group would certainly be helpful.

\section{Discussion \& Conclusion}

In order to underline the power of the MOL, the first aspect that will be discussed is the long term recall performance. The vast majority of participants in this study (who took part in the long term phase) scored substantially better results than indicated by the forgetting curve (Ebbinghaus (1885)). The forgetting curve shows the relation between the ability to recall rate in percent over time [14]. Ebbinghaus conducted a self-experiment and derived the famous curve, which was validated and confirmed by other authors in this research domain [41] (see figure 2). Note that some participants even scored more than $100 \%$ in the long term task. This is possible, as the students short term performance (in this case the lenient score) was the reference for the comparison with the long term performance. So, the achieved lenient score represented $100 \%$ regarding the calculation of the forgetting rate. In other words, after one week some students were able to remember more terms than right after the experiment.

Forgetting Curve (Ebbinghaus, 1885)

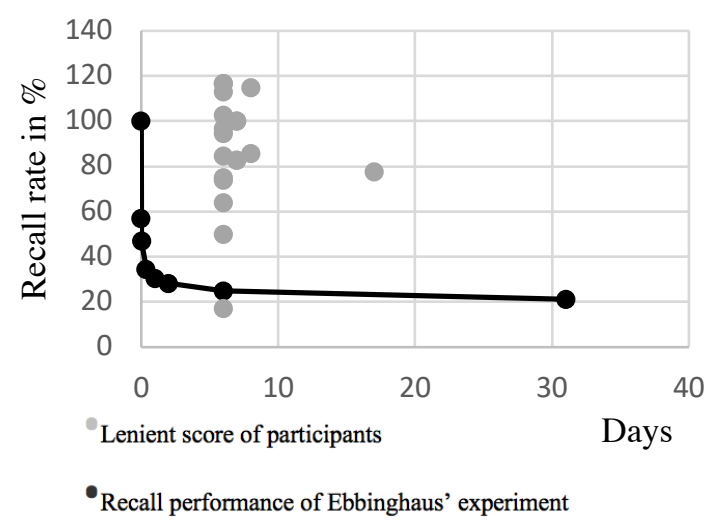
Figure 2. Lenient Score Results and
Ebbinghaus' forgetting curve 
The results of the data analysis showed mostly significant regression models for the assumed correlations. Hence, the hypotheses $\mathrm{H} 1, \mathrm{H} 2$ and $\mathrm{H} 4$ cannot be rejected at this point. The positive influence of the level of immersion on the strict score is only supported by a trend effect (H3).

However, it seems that the users' perceived usefulness, which is an important factor for the technology acceptance, is substantially driven by the recall performance. Therefore, further research in this promising domain shall be encouraged to strive for a more holistic concept of a VMP. As seen in section two, all related work mainly focused on research questions that involved only trivial loci. To this day, there are no studies that investigate a VMP which visualizes more complex learning content or implements further mechanisms to address higher levels of learning (cf. Bloom's Taxonomy, section one). Furthermore, the level of immersion has a positive influence on the recall performance. As seen in section three, this correlation was already suggested, partially analyzed and promoted by other studies $[18,19,20,24]$. However, in order to fully understand important immersion factors for the VMP concept, further research is certainly necessary. Possible research questions might evaluate which kind of immersion leveraging features suit best for this concept (e.g. intense interaction with the loci or auditory cues [12]).

\section{References}

[1] Agarwal, R., and E. Karahanna, "Time Flies When You're Having Fun: Cognitive Absorption and Beliefs about Information Technology Usage", MISQ 24(4), 2000, pp. 665.

[2] Awang, Z., W.M.A. Wan Afthanorhan, and M.A.M. Asri, "Parametric and Non Parametric Approach in Structural Equation Modeling (SEM): The Application of Bootstrapping”, Modern Applied Science 9(9), 2015.

[3] Backhaus, K., B. Erichson, R. Weiber, and W. Plinke, "Logistische Regression", In Multivariate Analysemethoden. Springer Berlin Heidelberg, Berlin, Heidelberg, 2016, 283356.

[4] Baskerville, R., A. Baiyere, S. Gregor, A. Hevner, and M. Rossi, "Design Science Research Contributions: Finding a Balance between Artifact and Theory", Journal of the Association for Information Systems, , pp. 19.

[5] Bloom, B.S., M.D. Engelhart, E.J. Furst, W.H. Hill, and D.R. Krathwohl, Taxonomy of Educational Objectives, Handbook I: The Cognitive Domain, David McKay Co Inc., New York, 1956.

[6] Bredl, K., A. Groß, J. Hünniger, and J. Fleischer, "The Avatar as a Knowledge worker? How immersive 3D virtual environments may foster knowledge acquisition", Leading Issues in Knowledge Management, Volume Two 2, 2012, pp. 222.

[7] Brehmer, Y., S.-C. Li, V. Mueller, T. von Oertzen, and U. Lindenberger, "Memory plasticity across the life span: Uncovering children's latent potential.", Developmental Psychology 43(2), 2007, pp. 465-478.

[8] Cohen, J., Statistical power analysis for the behavioral sciences, L. Erlbaum Associates, Hillsdale, N.J, 1988.

[9] Cohen, J., “QUANTITATIVE METHODS IN PSYCHOLOGY”, Psychological Bulletin 112(1), 1992, pp. $155-159$

[10] Cronbach, L.J., "Coefficient alpha and the internal structure of tests", Psychometrika(16), 1951, pp. 297-334.

[11] Davis, F.D., “A technology acceptance model for empirically testing new end-user information systems: Theory and results", 1985.

[12] Dede, C., "Immersive Interfaces for Engagement and Learning”, Science 323(5910), 2009, pp. 66-69.

[13] Dresler, M., W.R. Shirer, B.N. Konrad, et al., "Mnemonic Training Reshapes Brain Networks to Support Superior Memory", Neuron 93(5), 2017, pp. 1227- 1235.e6.

[14] Ebbinghaus, H., Über das Gedächtnis. Untersuchungen zur experimentellen Psychologie, Duncker \& Humblot, Leipzig, 1885.

[15] Fassbender, E., and W. Heiden, "The virtual memory palace", Journal of Computational Information Systems 2(1), 2006, pp. 457-464.

[16] Forza, C., and R. Filippini, "TQM impact on quality conformance and customer satisfaction: A causal model", International Journal of Production Economics 55(1), 1998, pp. 1-20.

[17] Hagström, J., and A. Winman, "Virtually overcoming grammar learning with 3D application of Loci mnemonics?", Applied Cognitive Psychology, 2018.

[18] Hair, J.F., W.C. Black, B.J. Babin, and R.E. Anderson, Multivariate Data Analysis, Pearson, Harlow, Essex, 2013.

[19] Hartwig, M.K., and J. Dunlosky, "Study strategies of college students", Psych. Bulletin\&Review 19(1), 2012, pp. $126-134$

[20] Hedman, A., and P. Bäckström, "Rediscovering the Art of Memory in Computer Based Learning-An Example Application", 2000. 
[21] Hettinger, L.J., and G.E. Riccio, "Visually induced motion sickness in virtual environments", Presence: Teleoperators \& Virtual Environments 1(3), 1992, pp. 306310 .

[22] Hevner, A.R., S.T. March, and S. Ram, "Design Science In Information Systems Research”, MIS Quarterly 28(1), 2004, pp. 75-105.

[23] Hu, L., and P.M. Bentler, "Cutoff criteria for fit indexes in covariance structure analysis: Conventional criteria versus new alternatives", Structural Equation Modeling: A Multidisciplinary Journal 6(1), 1999, pp. 1-55.

[24] Huttner, J.-P., and S. Robra-Bissantz, “A Design Science Approach to High Immersive Mnemonic Elearning”, MCIS 2016 Proceedings. 28., 2016.

[25] Huttner, J.-P., and S. Robra-Bissantz, “An Immersive Memory Palace: Supporting the Method of Loci with Virtual Reality", Americas Conference on Information Systems. 2017. Proceedings, 2017.

[26] Jund, T., A. Capobianco, and F. Larue, "Impact of Frame of Reference on Memorization in Virtual Environments", IEEE (2016), 533-537.

[27] Kanske, P., and S.A. Kotz, "Leipzig Affective Norms for German: A reliability study", Behavior Research Methods 42(4), 2010, pp. 987-991.

[28] KILDUFF, M., A. MEHRA, and M.B. DUNN, "From Blue Sky Research to Problem Solving: A Philosophy of Science Theory of New Knowledge Production", Academy of Management Review, 2011, pp. 21.

[29] Kline, R.B., Principles and practice of structural equation modeling, Guilford Press, New York, 2005.

[30] Krathwohl, D.R., “A Revision of Bloom's Taxonomy: An Overview", Theory Into Practice 41(4), 2002, pp. $212-$ 218.

[31] Krokos, E., and A. Varshney, "Virtual Memory Palaces: Immersion aids Recall”, 2015.

[32] Legge, E.L.G., C.R. Madan, E.T. Ng, and J.B. Caplan, "Building a memory palace in minutes", Acta Psychologica 141(3), 2012, pp. 380-390.

[33] Levenshtein, V.I., "Binary Codes Capable of Correcting Deletions, Insertions and Reversals", Soviet Physics Doklady(Vol. 10), , pp. 707-709.

[34] Lin, J.J.-W., H.B. Duh, D.E. Parker, H. Abi-Rached, and T.A. Furness, "Effects of field of view on presence, enjoyment, memory, and simulator sickness in a virtual environment", Virtual Reality, 2002. Proceedings. IEEE, IEEE (2002), 164-171.
[35] Liu, L., R. Ip, A. Shum, and C. Wagner, "Learning Effects of Virtual Game Worlds: An Empirical Investigation of Immersion, Enjoyment and Performance”, 2014.

[36] Maguire, E.A., E.R. Valentine, J.M. Wilding, and N. Kapur, "Routes to remembering: the brains behind superior memory”, Nature Neuroscience 6(1), 2002, pp. 90-95.

[37] Mania, K., and A. Chalmers, "The effects of levels of immersion on memory and presence in virtual environments: A reality centered approach", CyberPsychology \& Behavior 4(2), 2001, pp. 247-264.

[38] Mann, J., N. Polys, R. Diana, M. Ananth, B. Herald, and S. Platel, "Virginia tech's study hall: A virtual method of loci mnemotechnic study using a neurologically-based, mechanism-driven, approach to immersive learning research”, Virtual Reality (VR), 2017 IEEE, IEEE (2017), 383-384.

[39] Martín-Gutiérrez, J., "Virtual Technologies Trends in Education”, EURASIA Journal of Mathematics, Science and Technology Education 13(1), 2017.

[40] McCabe, J., "Metacognitive awareness of learning strategies in undergraduates", Memory \& Cognition 39(3), 2011, pp. 462-476.

[41] Murre, J.M.J., and J. Dros, "Replication and Analysis of Ebbinghaus' Forgetting Curve”, PLOS ONE 10(7), 2015, pp. e0120644.

[42] Peffers, K., T. Tuunanen, M.A. Rothenberger, and S. Chatterjee, "A Design Science Research Methodology for Information Systems Research", Journal of Management Information Systems 24(3), 2007, pp. 45-77.

[43] Putnam, A.L., "Mnemonics in education: Current research and applications.", Translational Issues in Psychological Science 1(2), 2015, pp. 130-139.

[44] Ragan, E.D., D.A. Bowman, and K.J. Huber, "Supporting cognitive processing with spatial information presentations in virtual environments", Virtual Reality 16(4), 2012, pp. 301-314.

[45] Ragan, E.D., A. Sowndararajan, R. Kopper, and D.A. Bowman, "The Effects of Higher Levels of Immersion on Procedure Memorization Performance and Implications for Educational Virtual Environments", Presence: Teleoperators and Virtual Environments 19(6), 2010, pp. 527-543.

[46] Ralby, A., M. Mentzelopoulos, and H. Cook, "Learning Languages and Complex Subjects with Memory Palaces", In D. Beck, C. Allison, L. Morgado, et al., eds., Immersive Learning Research Network. Springer International Publishing, Cham, 2017, 217-228.

[47] Roediger, H.L., "The effectiveness of four mnemonics in ordering recall.", Journal of Experimental Psychology: Human Learning and Memory 6(5), 1980, pp. 558. 
[48] Ross, J., and K.A. Lawrence, "Some observations on memory artifice”, Psychonomic Science 13(2), 1968, pp. $107-108$.

[49] Witmer, B.G., and M.J. Singer, "Measuring presence in virtual environments: A presence questionnaire", Presence 7(3), 1998, pp. 225-240.
[50] Wong, J., and P. Storkerson, "Hypertext and the Art of Memory”, Visible Language 31(2), 1997, pp. 126-157.

[51] Yates, F.A., The art of memory, Routledge, London ; New York, 1999. 